\title{
PANORAMAS RECENTES DO FEMINISMO NA INTERSECCIONALIDADE ${ }^{1}$
}

Resumo: O presente artigo foi redigido originalmente em inglês, cujo título é Recent feminist outlooks on intersectionality, de autoria da professora e pesquisadora Sirma Bilge, publicado na Diogenes. Trata-se de uma discussão interessada em teorizar o conceito de interseccionalidade a partir da operacionalização do gênero nos estudos feministas.

Palavras-Chave: Feminismo. Interseccionalidade. Gênero.

\section{RECENT FEMINIST OUTLOOKS ON INTERSECTIONALITY}

Abstract: This article was originally written in English and its title is Recent feminist outlooks on intersectionality, by professor and researcher Sirma Bilge, published in Diogenes. It is a discussion that focuses on the theorizing the concept of intersectionality from the operationalization of gender in feminist studies.

Keywords: Feminism. Intersectionality. Gender.

\section{LES RÉCENTES PERSPECTIVES FÉMINISTES SUR L'INTERSECTIONNALITÉ}

Résumé: Cet article a été écrit à l'origine en anglais et son titre est Recent feminist outlooks on intersectionality, par la professeure et chercheuse Sirma Bilge, publié dans Diogenes. C'est une discussion qui s'intéresse à la théorisation du concept d'intersectionnalité à partir de l'opérationnalisation du genre dans les études féministes.

Mots-clés: Féminisme. Intersectionnalité. Le genre.

\section{PERSPECTIVAS FEMINISTAS RECIENTES SOBRE LA INTERSECCIONALIDAD}

Resumen: Este artículo fue escrito originalmente en inglés y titulado Recent feminist outlooks on intersectionality, por la profesora e investigadora Sirma Bilge, publicado en Diógenes. Se trata de un debate sobre la teorización del concepto de interseccionalidad a partir de la operacionalización del género en los estudios feministas.

Palabras clave: El feminismo. Interseccionalidad. El género.

\section{Introdução}

Precedendo ao lançamento de uma edição especial para o novo milênio, uma das revistas mais importantes no campo dos estudos feministas, Signs: A Journal of Women in Culture and Society ${ }^{3}$ (Sinais: Uma Revista de Mulheres na Cultura e na

\footnotetext{
${ }^{1}$ Referência original: BILGE, Sirma. Recent feminist outlooks on intersectionality. Diogenes, v. 57, n. 1, p. 58-72, 2010. O processo de revisão técnica da tradução foi realizado pelo prof. Dr. Marcus Vinicius Reis - UNIFESSPA - Orcid: https://orcid.org/0000-0002-5972-1289.

2 Ph.D., Professora Associada, Departamento de Sociologia, Universidade de Montreal, C.P. 6128, Succursale Centre-ville, H3C 3J7. Montreal (Qc) Canadá. E-mail: sirma.bilge@umontreal.ca. Gostaria de agradecer a Oliver Roy, Candidato a Ph.D. em Sociologia na Université de Montréal por sua valiosa assistência na pesquisa de documentos.

${ }^{3}$ A edição especial "Feminismos no Milênio", Signs, 25 (4), 2000.
} 
Sociedade), no ano 2000, pediu que 55 pesquisadoras, antigas editoras ou membros do comitê internacional de revisão, pensassem no assunto que particularmente gostariam de ver em destaque para o próximo milênio. O resultado foi revelador: entre as 55 respostas, a natureza da "interseccionalidade" e a necessidade de abordar questões teóricas, empíricas e do ativismo a seu respeito, foi citada várias vezes, ocasionalmente através de termos associados como "desigualdade complexa", "diferença" ou "diversidade". Ademais, levar em conta as intersecções entre raça, classe e gênero foi algo identificado como alinhado às atuais "boas práticas feministas" na academia (WEBER; PARRA MEDINA, 2003, p. 223-224). Mais recentemente, a interseccionalidade é tida como a contribuição teórica mais importante do feminismo recente (MCCALL, 2005, p. 1771), por sua investida em lidar com as diferenças e complexidades que emergem da geração da teoria, mantendo o ímpeto político do feminismo (KNAPP, 2005, p. 254), ou novamente como uma das quatro principais perspectivas da terceira onda feminista, juntamente com as abordagens pósestruturalistas e pós-modernas, a teoria feminista pós-colonial e as prioridades da geração mais jovem (MANN; HUFMANN, 2005, p. 57). A interseccionalidade reflete a teoria transdisciplinar que busca compreender a complexidade das identidades sociais e desigualdades através de uma abordagem integrada. Tal teoria refuta a compartimentação de hierarquização dos grandes eixos de diferenciação social através de categorias de gênero/sexo, classe, raça, etnia, deficiência e orientação sexual.

A abordagem interseccional vai além do simples reconhecimento da multiplicidade dos sistemas de opressão, funcionando para além dessas categorias, e apresenta suas interações na produção e reprodução de desigualdades sociais (CRENSHAW, 1989; COLLINS, 2000; BRAH; PHOENIX, 2004). Propõe-se a compreensão da realidade social de homens e mulheres juntamente com as dinâmicas sociais, culturais, econômicas e políticas associadas a ela como múltiplas e determinadas simultânea e interativamente através de vários eixos "significantes" de organização social (STASIULIS, 1999, p. 345).

Oriunda do trabalho pioneiro de feministas negras nos Estados Unidos e GrãBretanha sobre a interligação hierárquica das relações de dominação (raça/gênero/classe ${ }^{4}$ ), a interseccionalidade se tornou o termo preferido nos círculos acadêmicos e ativistas anglófonos para designar a complexa “interwriting” de

\footnotetext{
${ }^{4}$ Essa genealogia nem sempre é aceita com unanimidade, como será mostrado mais adiante.
} 
identidades múltiplas identidades / desigualdades ${ }^{5}$.

Os primeiros estudos permitiram que o locus social das "mulheres de cor" emergisse da invisibilidade, um locus que se encontrava marginalizado tanto dentro do feminismo quanto dos movimentos antirracistas. Trabalhos contemporâneos são cada vez mais direcionados para a elaboração de um instrumento interseccional através do quais políticas de justiça social e mecanismos para enfrentar a discriminação podem ser transformados Esse projeto suscitou debates em dois níveis diferentes: em um nível, em relação à geração de conhecimento acerca da interseccionalidade e a maneira como a pesquisa interseccional deve ser realizada (questões de teoria e metodologia), e outro nível associados às maneiras como esse conhecimento é ou deveria ser mobilizado em lutas políticas por igualdade e como tais lutas podem ser afetadas. Neste artigo me limitarei à primeira dessas áreas de debate a fim de definir os pontos de tensão que me parecem centrais nas teorizações atuais acerca da interseccionalidade. Essa investida tem um objetivo duplo: apontar certas limitações do poder de explicação da interseccionalidade e trazer à tona outras linhas de pesquisa à luz de discussões atuais. Tendo isso em vista, abordarei quatro pontos: a interseccionalidade como paradigma para pesquisa, a questão dos níveis de análise, a disputa teórica pelo status ontológico das categorias de diferenciação e a questão da ampliação do alcance teórico da interseccionalidade.

\section{A Interseccionalidade como Paradigma}

Se Patricia Hill Collins (2000, p. 257;297), uma das teóricas chave do pensamento do feminismo negro foi a primeira a referir-se à interseccionalidade como um paradigma, foi a cientista política Ange-Marie Hanock que propôs como ela pode der formulada. Para isso, é necessário ir além da concepção da interseccionalidade como uma especialização baseada em conteúdo que, ainda sim, permitiu a observação das subjetividades das mulheres que residem nas interseções de múltiplas categorias de diferenciação e marginalização, particularmente o caso de mulheres negras, ao ponto de poder ser vista como um paradigma, ou seja, "um corpo de teoria normativa e pesquisa empírica" (HANCOCK, 2001, p. 250-251). Para tanto, Hancock propõe seis pressupostos básicos: 1. Mais de uma categoria de diferença desempenha um papel em

\footnotetext{
${ }^{5}$ A dualidade do objeto interseccional, sendo percebido em termos de identidade ou estrutura, passa por toda a literatura e constitui um ponto de tensão recorrente a níveis nacionais.
} 
problemas e processos políticos complexos; 2. Todas as categorias de diferença pertinentes devem ser abordadas, mas as relações entre tais categorias são variáveis e continuam sendo uma pergunta empírica aberta; 3. Essas categorias da diferença são definidas como produtos dinâmicos de fatores individuais e institucionais, simultaneamente contestadas e mantidas a nível individual e institucional; 4. Cada categoria de diferença é caracterizada por uma diversidade dentro do grupo; 5 . Um projeto de pesquisa interseccional examina categorias em múltiplos níveis de análise e questiona as interações entre níveis; 6. Apresentar a interseccionalidade como um paradigma normativo e empírico requer atenção tanto para os aspectos teóricos quanto para os empíricos da pesquisa em questão (HANCOCK, 2001, p. 250-251). Para Hancock (2007, p. 249-250), esse movimento em direção a um nível de análise mais amplo, embora ainda vinculado à necessidade de analisar situações específicas e concretas, permite uma resposta mais compreensiva para as questões da justiça distributiva, poder e governo. Sua posição encontra resultados favoráveis de dentro da pesquisa interseccional, notavelmente nos Estados Unidos e no Canadá6, o que se diferencia da pesquisa europeia pela ênfase que coloca em aspectos estruturais, um ponto a ser desenvolvido mais adiante.

Para outras pesquisas que estão vindo de uma perspectiva da sociologia da ciência, o objetivo de estabilizar a interseccionalidade não é necessariamente bom na medida em que a ambiguidade que circunda esse conceito não é de todo uma desvantagem; muito pelo contrário, a força da interseccionalidade está precisamente em ser suficientemente vaga pra reunir duas das mais importantes vertentes do pensamento feminista contemporâneo que estiveram, de muitas maneiras, interessadas na questão da diferença: a teoria feminista negra e o pensamento feminista pós-moderno/ pósestruturalista (DAVIS, 2008, p. 70-71). Como veremos mais adiante, a aproximação entre as duas vertentes no que tange à interseccionalidade não se deu sem alguns atritos pelo caminho: divisões teóricas significativas estão alinhadas dentro dessas duas tradições do pensamento e sustentam muitas discussões ontológicas e epistemológicas.

\section{A Questão dos Níveis de Análise}

Para um bom número de autores, a interseccionalidade deveria fornecer uma estrutura analítica que permita levar em conta tanto questões macrossociológicas quanto

\footnotetext{
${ }^{6}$ Para uma revisão do trabalho de feministas canadenses que, na década de 1980, abordaram questões que hoje seriam consideradas interseccionais, mas sem usar o termo, ver Denis (2008).
} 
microssociológicas. A análise interseccional opera em dois níveis. No nível microssocial, através da consideração do intercruzamento de categorias sociais e as múltiplas fontes de poder e privilégio, permite que os efeitos das estruturas de desigualdade nas vidas individuais sejam abordados juntamente com a maneira com que as suas interseções produzem configurações únicas. A nível macrossocial, são questionadas as formas como múltiplos sistemas de poder estão envolvidos na produção, organização e manutenção de desigualdades (HENDERSON; TICKMAYER, 2009; WEBER, 2001). A análise interseccional, portanto, vai "além de enxergar a natureza integrada e fluida das categorias sociais da experiência" ao abordá-las como "parte de uma ampla estrutura de macro e micro relações, instituições e processos que estão envolvidos na construção social da desigualdade" (HANKIVSKY; CHRISTOFFERSEN, 2008, p. 277).

Essa dualidade analítica do macro/micro que caracteriza o pensamento interseccional é marcada por Collins como uma distinção lexical: ela emprega o termo interseccionalidade para denotar as formas particulares assumidas pelo complexo de opressões interligadas nas experiências de vida de indivíduos, e o termo matriz de dominação para designar suas organizações sociais (COLLINS, 2000, p. 18). Contudo, sua abordagem vai além de uma simples análise a dois níveis, defendendo a inclusão de quatro domínios de poder em seu interior que, em sua visão, estão presentes em todas as formas de opressão, a despeito da diversidade de suas configurações interseccionais. Esse é um assunto que pretendo retomar.

Pode ser apontado que o debate acerca dos níveis de análise micro/macro é marcado por uma divergência de opiniões: de fato, segundo alguns autores, a análise interseccional pode estar demasiadamente focada em apenas um dos dois níveis. Porém, para a psicóloga dinamarquesa Dorthe Staunaes (2003, p. 101), uma reestruturação do conceito à luz de escritos pós-estruturalistas e socioconstrutivistas sobre a construção do sujeito (subjetivação) é necessária, no sentido de que o paradigma da interseccionalidade possivelmente está comprometido por sua excessiva dependência da noção de estruturas, em detrimento da análise das dimensões subjetivas das relações de poder desiguais. Em contraste, Collins (2009, p. IX) expressa o receio de que, nos últimos anos, as análises interseccionais se tornaram excessivamente voltadas para dentro, concentrando-se demasiadamente em narrativas identitárias. Ainda que reconheça a relevância material que essa tendência está trazendo ao processo de apreensão da interseccionalidade, Collins não está de acordo com o abandono de 
abordagens estruturais nos estudos de desigualdades sociais, o que ela atribui à ascensão de análises pós-estruturalistas da desigualdade, e ressalta a urgência de recentralizar a atenção na análise sócioestrutural, especificamente nas manifestações organizacionais e institucionais das assimetrias de poder.

Essa clivagem entre as abordagens macro e micro não está desligada da suposta dupla filiação, que é em si um assunto de controvérsia: a decadente relação entre a interseccionalidade e o pensamento feminista negro parece ser amplamente reconhecida (CRENSHAW, 1989; COLLINS, 2000; BRAH; PHOENIX, 20047), mas a conexão com o pensamento pós-moderno/pós- estruturalista permanece em debate.

Mesmo dentro dessa tendência em particular, há potenciais leituras divergentes: se para Kimberlé Crenshaw ${ }^{8}$ (1991, p. 1244-1245), a interseccionalidade é um conceito funcional que liga a política contemporânea à teoria pós-moderna, para Patricia Hill Collins a mesma constitui um paradigma alternativo ao antagonismo entre o positivismo e o pós-modernismo que foi parte das dicotomias estruturantes da epistemologia ocidental (Collins, 2000: 296).

Essa filiação teórica dupla da interseccionalidade mostra diferentes configurações, dependendo dos contextos nacionais. Enquanto nos Estados Unidos, a maioria das produções acadêmicas acerca da interseccionalidade são fortemente influenciadas pelo pensamento feminista negro, em cujo coração a tradição neomarxista continua sendo predominante, na Europa, e particularmente nos países Nórdicos e na Holanda, a interseccionalidade se aproxima mais à ala pós-moderna. Essa associação ao pensamento pós-estruturalista e suas ferramentas conceituais leva, nos melhores casos, a um avanço inegável do paradigma interseccional, notavelmente na formação de

\footnotetext{
7 Deve-se ressaltar que uma aproximação excessiva da interseccionalidade com mulheres AfroAmericanas é uma postura que foi criticada por seu reducionismo. De acordo com Lykke, a ligação apresentada por Bell Hooks (nome profissional de Gloria Jean Watkins, nota da autora) que associa a interseccionalidade ao feminismo negro, não reconhece a contribuição de feministas socialistas e marxistas na Europa, que desde a década de 197 estavam examinando as interseções entre as relações de gênero/sexo e as relações de classe. É exatamente no sentido dessa crítica que é possível ler a colocação de Walby (2007, p. 450): "interseccionalidade é um termo relativamente novo para descrever uma questão antiga na teorização das relações entre diferentes formas de desigualdade social". Os esforços para visibilizar os estudos feministas dos anos 1970 e 1980 que tratavam de divisões sociais articuladas refletem, também, um certo desejo de trazer à tona a possível filiação múltipla de um paradigma que parece ter se tornado firmemente estabelecido na literatura atual.

${ }^{8}$ Uma figura proeminente do Critical Race Feminism (Feminismo Negro) que se levantou reagindo ao etnocentrismo da escola de estudo legais críticos e à indiferença daqueles associados à teoria racial crítica acerca do gênero e da desigualdade, a professora de direito afro-americana Crenshaw foi a primeira a usar o termo interseccionalidade em 1989. Sua abordagem distingue entre a interseccionalidade estrutural (i.e. marginalização baseada em barreiras estruturais) e a interseccionalidade política (i.e. marginalização baseada no pertencimento a grupos com interesses políticos conflitantes).
} 
estruturas conceituais originais e fortemente relevantes e sua aplicação na pesquisa por métodos qualitativos.

Contudo, em uma análise muito cuidadosa das narrativas identitárias de jovens mulheres marroquinas imigrantes na Holanda, Buitelaar (2006, p. 273) utiliza o conceito do "self dialógico" (BAKHTIN, 1981; HERMANS; KEMPEN, 1993) para examinar suas identificações interseccionais na forma de diálogos entre as múltiplas vozes do self, onde cada uma dessas vozes é perpassada por repertórios de práticas e discursos informados por relações de poder específicas - uma demonstração empírica bem sucedida das maneiras com que "identificações particulares são sempre coconstruídas com outras categorias de identidade" (BUITELAAR, 2006, p. 273). Também pode-se mencionar o trabalho de Kofoed (2008), que ativa com êxito uma estrutura analítica interseccional em conjunto com uma epistemologia pós-estruturalista da normalidade/desvio dentro da área das ciências da educação. Aplicando métodos de investigação qualitativa (observação e entrevistas) em uma escola primária em Copenhagen, a autora interroga sobre o status do futebol como um espaço institucional de masculinidade e examina o processo de inclusão e exclusão que mobiliza categorias interseccionais na seleção de jogadores nos times de futebol. Sua análise revela não só o caráter enraizado das categorias sociais mais frequentemente estudadas como raça, gênero e classe, mas também aponta outros eixos de diferenciação menos problematizados, como aparência física e aptidão acadêmica e esportiva.

Embora os estudos de Buitelaar e Kofoed mostrem que a interseccionalidade pode estar funcionalmente ligada a ferramentas conceituais inspiradas de várias formas pelo pós estruturalismo, de maneira a fortalecer a fundamentação da interseccionalidade como paradigma de pesquisa, ainda não se pode generalizar a pertinência de tal associação. A título de exemplo, certas associações precipitadas entre a interseccionalidade e o trabalho de Foucault me parecem problemáticas. Para Susanne Knudsen (2006, p. 61), especialista em educação e estudos midiáticos, a questão do poder, inspirada por Foucault, está no cerne do conceito de interseccionalidade. Essa perspectiva é compartilhada pela socióloga da ciência Kathy Davis, segundo a qual "a interseccionalidade se encaixa perfeitamente no projeto pós-moderno de conceptualizar identidades múltiplas e mutáveis. Coincidiu com as perspectivas foucaultianas do poder, focadas em processos dinâmicos e na desconstrução de categorias moralizantes e homogeneizantes (2008, p. 71; STAUNAES, 2003). Mas, associar diretamente a interseccionalidade à concepção foucaultiana de poder e dominação parece discutível na 
medida em que Foucault sempre se recusou a especificar um princípio de dominação (raça, classe ou gênero) e apontar um sujeito ou grupo de sujeitos como fonte do poder ${ }^{9}$ (HALL, 1997); como resultado, tal associação demanda considerações teóricas muito mais aprofundadas do que se pode encontrar atualmente na literatura.

Ademais, a ligação entre a interseccionalidade e o pensamento pós-moderno precisa ser entendida de forma longitudinal e não-estática, assim, como Vakulenko (2007, p. 185) coloca, as questões levantadas pelo pensamento pós-moderno como identidade e essencialismo e a reificação de categorias, inicialmente consideradas críticas à interseccionalidade, posteriormente foram incorporadas à definição e entendimento contemporâneos do que constitui a abordagem interseccional.

Finalmente, percebida como associada ao pós-modernismo ou separada do mesmo, uma coisa me parece clara: o crescimento da interseccionalidade foi facilitado pela dúvida lançada sobre as verdades científicas e as críticas ao positivismo encorajadas pelo pós-modernismo, que, na sociologia contemporânea, levou ao descarte de explicações unidimensionais da desigualdade social e o aumento do interesse em questões de desigualdade complexa e discriminação múltipla (THERBORN, 2000).

A esse respeito, é apropriado pausar brevemente para considerar as aparentes diferenças no entendimento, uso e receptividade da interseccionalidade. A distinção mais óbvia pode ser observada entre trabalhos publicados dos países nórdicos, onde a interseccionalidade, como já vimos, está mais associada ao pós-estruturalismo e mobilizada em análises dos processos de subjetivação; e a pesquisa norte-americana, onde o conceito é usado principalmente em análises estruturais da desigualdade. A abordagem norte-americana traz a interseccionalidade como "um campo emergente e inovador de investigação, que fornece lentes analíticas e críticas para interrogar disparidades sociais ligadas à raça, etnia, classe, deficiência, idade, sexualidade e gênero, e para desafiar métodos de explicar essas estruturas de desigualdade" (DILL; ZAMBANA, 2009, p. 1). Um maior peso é dado, portanto, à análise do impacto do sistema ou estrutura em relação à análise da formação de identidades. A academia

\footnotetext{
${ }^{9}$ Pode ser observado a esse respeito que a análise do poder no trabalho de Foucault (1997, p. 39) busca "traduzir as relações de poder e os operadores da dominação em termos históricos e empíricos" "ao invés de ver os poderes como derivados da soberania". A abordagem de Foucault começada relação de poder em si, e não dos sujeitos, mostrando como essas relações de sujeição criam sujeitos. A tarefa seria "desnudar as relações de dominação e permitir que se revelem em sua multiplicidade, sua diferença, sua especificidade ou sua reversibilidade: não buscar, consequentemente um tipo de fonte soberana de todos os poderes; pelo contrário, mostrar como diferentes operadores de dominação dependem uns dos outros, em alguns casos reforçando-se e convergindo, e em outros casos contradizendo-se, tendendo a se cancelar" (FOUCAULT, 1997, [grifo da autora]).
} 
britânica, por outro lado, concentra-se nos aspectos dinâmicos e relacionais da identidade social (PRINS, 2006, p. 279). Essas diferenças "nacionais" refletem, em termos gerais, a persistência da tensão entre ator e estrutura para se entender e aplicar a interseccionalidade como um paradigma de pesquisa.

Como podem, portanto, ser evitados o impasse ator/estrutura e análises que dividem micro e macro? Caminhos interessantes foram propostos por diversos autores (WALBY, 2007; YUVAL-DAVIS, 2006; KNAPP, 2005; COLLINS, 2000) a fim de esquivar-se da armadilha dos argumentos dicotômicos em questão e de ampliar o alcance teórico da interseccionalidade. Mas, antes de examinar tais caminhos, faz-se apropriado levar em consideração um conflito teórico em que baseiam suas afirmações.

\section{Conflito Teórico no Status Ontológico de Categorias de Diferença}

Se a interação de categorias de diferença constitui uma área de consenso na literatura da interseccionalidade - como testemunhado pelo uso de termos referentes às categorias/identidades/processos "mutuamente constitutivos" - a questão ontológica ( $o$ que é?) e a pergunta epistemológica (como vemos?) estão sujeitas à controvérsia. Uma certa vagueza de fato rodeia a noção "mutuamente constitutivo". O que é considerado mutuamente constitutivo? Estamos falando das categorias de diferença/identidade ou dos processos que as trazem à tona? Dizer que são mutuamente constitutivas implica que uma não pode existir (ou nunca existiu) sem a outra? Essas relações mutuamente constituídas são simétricas? Ou podem ser assimétricas, sendo que uma relação de dominação super-determina as outras em certos contextos e sob certas condições?

Enquanto a literatura atual sobre o assunto rompeu com a postura dogmática que rejeita qualquer hierarquização (assimetria de poder) entre os eixos de divisão social ${ }^{10}$, até mesmo se houver justificação empírica, nem sempre se projeta uma luz ontológica ou epistemológica sobre o que é mutuamente constitutivo. De fato, muitos textos se contentam com uma afirmação em princípio, reduzindo a interseccionalidade e a ideia de categorias de diferença co-constitutivas a uma simples fórmula desprovida de

\footnotetext{
10 A rejeição categórica à hierarquização dos eixos de desigualdade social (raça, gênero, classe) foi particularmente característica da fase inicial da interseccionalidade (dos anos 1980 a meados dos anos 1990). Levando em conta a época, essa rejeição é compreensível como um ato político de resistência contra as abordagens monistas à dominação social que discuto em outros trabalhos (BILGE, in press). Tais abordagens agrupam por pressupostos ideológicos as diferentes relações de desigualdade sob uma causa abrangente, um fator dominante fundamental (seja a exploração capitalista, o patriarcado ou o racismo) do qual se acredita que todos os outros saem. Hoje, a orientação preponderante deixa as relações entre as categorias de diferenciação como uma pergunta aberta a ser verificada empiricamente (HANCOCK, 2007).
} 
substância. A socióloga canadense Daiva Stasiulis identificou esse problema há dez anos e lamentou a atitude tokenista que consistia simplesmente em elaborar listas de diferenças. Posteriormente, no contexto de uma difusão muito maior do conceito para além do mundo anglo-americano, particularmente no mundo nórdico e de língua alemã, a socióloga alemã Gudrun-Axeli Knapp (2005) generalizou essa crítica, declarando que a notável popularidade da interseccionalidade não estava desconectada à superficialidade de alguns de seus usos. Para ela, a reificação da interseccionalidade em "meramente uma fórmula a ser mencionada, largamente despojada de sua bagagem de concretude, de contexto e de história, foi uma condição de possibilidade de sua aceleração” (KNAPP, 2005, p. 255). Em tais circunstâncias, a interseccionalidade se torna comparável a um "discurso doxográfico", sendo um "discurso de segunda ordem ou meta-teórico no qual as teorias tendem a movimentar-se como entidades taxonômicas" (KNAPP, 2005, p. 254), cuja durabilidade e carreira no "mercado de citações" repousa em um imperativo secreto identificado por Derrida (1990, p. 75): "não use esse conceito, apenas mencione-o" (KNAPP, 2005, p. 252, 254).

Entre os estudos que procuram conceituar a relação entre diferentes categorias de desigualdades, um debate central dirige-se ao status ontológico de tais categorias. Trata-se de fenômenos dotados de um certo grau de autonomia entre si ou são inseparavelmente conectados? Aqui, ambas as questões ontológica e epistemológica se entrelaçam, alguns optam por definições que unem o objeto de análise e a maneira de enxergá-lo. Um certo número de autores enfatiza a importância das dissociações analíticas entre as categorias da diferença (como se pensa e como se estuda?), ainda reconhecendo que "no mundo real, indivíduos vivem essas categorias simultaneamente" (sobre o que é ?). Essa tendência é particularmente presente nos estudo britânicos onde há forte ligação a um importante princípio de análise sociológica: a especificidade de um fenômeno dentro de sistemas sociais (MCALL, 1990, p. 216). Enfatiza-se, consequentemente, as distinta e irredutíveis bases ontológicas das diferentes categorias de desigualdade social e critica-se a pesquisa que não leva em conta suas ontologias e histórias específicas (ACKER, 2006b; ATHIAS; YUVAL-DAVIS, 1992; YUVALDAVIS, 2006). Também há receio de que a recusa em reconhecer uma hierarquia de relações de dominação pode levar às relações serem tomadas como padronizadas entre si, gerando conclusões descontextualizadas e a-históricas.

Anthias e Yuval-Davis (1992), em sua pesquisa anterior, afirmaram que cada eixo de divisão social possui uma base ontológica irredutível e relembraram que esses 
eixos são construções sócio-históricas interconectadas entre si. Em um artigo mais recente, Yuval-Davis revisita sua conceituação:

\begin{abstract}
A base ontológica de cada uma dessas divisões é autônoma e cada uma prioriza uma diferente esfera das relações sociais (...) Por exemplo, as divisões de classe estão fundadas em relação a processos econômicos de produção e consumo; o gênero deve ser entendido não como uma diferença social "real" entre homens e mulheres, mas como um modo de discurso relacionado a grupos de sujeitos cujos papéis sociais são definidos por suas diferenças sexuais/biológicas (...). Divisões étnicas e raciais relacionam-se a discursos de coletividades construídas em torno de limites de exclusão/inclusão. (YUVAL-DAVIS, 2006 p. 200-201)
\end{abstract}

Embora os esforços empregados a fim de atentar a análise interseccional às bases ontológicas de cada eixo de divisão social sejam considerados "um passo na direção certa" (WALLBY, 2007, p. 454), tal análise continua recebendo críticas por sua fragilidade teórica. Para a socióloga britânica Sylvia Walby, essa abordagem, que ela caracteriza como "reducionismo segregacionista", é preferível às outras ${ }^{11}$, mas também lhe falta coerência a nível teórico, no que confere a cada eixo/categoria de desigualdade social uma fundação ontológica distinta e irredutível ao mesmo tempo em que considera esses eixos como mutuamente constitutivos. Como podem essas categorias, tendo bases ontológicas separadas, em teoria mutuamente, constituir umas às outras, pergunta Walby (2007, p. 453), que sugere melhorar essa abordagem de duas maneiras. Porém, dado que estes caminhos para o refinamento teórico da interseccionalidade estão inscritos no quadro mais geral dos debates acerca dos limites do alcance explicativo da interseccionalidade e da sua ampliação, analisarei este assunto na próxima seção.

\title{
Como Ampliar o Alcance Teórico da Interseccionalidade?
}

Como mencionado acima, a busca por soluções para transcender as oposições binárias entre as análises de ator/estrutura ou micro/macro se encaixa na problemática mais geral da capacidade explicativa da interseccionalidade: a última é de fato suficiente como teoria para analisar tudo o que aspira (FABER, 2005; GIMENEZ, 2001)? Um

\footnotetext{
${ }^{11}$ As outras quatro tendências que Walby (2007, p. 451-453) identifica na literatura interseccional são: a crítica às generalizações excessivas que escondem as divisões internas dentro das categorias; $\mathrm{o}$ reducionismo a um eixo primário único da desigualdade social do qual os outros eixos derivariam, que eu caracterizo como uma abordagem monista (BILGE, in press); o micro reducionismo que rejeita qualquer conceptualização sistêmica das relações sociais e privilegia o estudo etnográfico de interseções específicas - uma abordagem que Walby atribui a um reducionismo cultural e uma inabilidade de explicar fenômenos mais amplos; a rejeição às categorias como um todo, com base na ideia de que as mesmas nunca representarão adequadamente o mundo vivido e são algo negativo por sua potencial calcificação na prática - uma abordagem problemática de acordo com Walby por se tratar de uma desconstrução radical das categorias que complica toda a análise baseada na distinção entre categorias.
} 
número de autores enfatiza a necessidade de algum refinamento teórico: para alguns, os níveis de análise precisam se tornar mais complexos (YUVAL-DAVIS, 2006; COLLINS, 2000); para outros, conexões precisam ser feitas entre a interseccionalidade e teorias sociais mais gerais (e.g. KNAPP, 2005; WALBY 2007).

Entre as autoras que desejam ir além dos níveis de análise mais discutidos na literatura, notavelmente na divisão macro/micro, pode-se citar Patricia Hill Collins e Nira Yuval-Davis. Do ponto de vista de Collins, o método interseccional deve levar em conta quatro domínios do poder: estrutural (leis e instituições), disciplinário (manejo administrativo e burocrático), hegemônico (naturalização cultural e ideológica das relações de dominação) e interpessoal (interações cotidianas influenciadas por múltiplas hierarquias) (COLLINS, 2000, p. 18; 277-290). Para Yuval-Davis (2006, p. 198), a análise interseccional deve encaixar-se em uma abordagem constitutiva, que não seja aditiva, através da qual as divisões sociais são analisadas em suas dimensões macro e micro, a partir da aplicação de uma estrutura analítica de quatro níveis: análise organizacional, relacionada às instituições e organizações sociais, políticas e econômicas; análise intersubjetiva, para estabelecer as relações de poder e afeto entre atores concretos em situações informais ou institucionais; análise experiencial, referente à experiência subjetiva de indivíduos, à percepção que os mesmos tem de si e suas atitudes em relação aos outros; e a análise representacional, referente ao nível das representações culturais das divisões sociais presentes na sociedade. Além da divisão binária entre o material e o simbólico, encontrada por exemplo no trabalho de Maynard (1994), os parâmetros delimitados por essas duas autoras percebem as relações sociais constitutivas de cada um desses quatro níveis de análise como sendo produzidas/reproduzidas tanto material quanto simbolicamente, e tendo efeitos tanto materiais quanto simbólicos.

O outro caminho proposto para o refinamento teórico da interseccionalidade consiste na integração com teorias sociológicas de referência mais geral. Nesse panorama, duas posturas diferentes podem ser observadas no que diz respeito às relações entre os eixos de divisão social: a primeira abordagem coloca, ainda que de maneira menos explícita que no passado, uma certa hierarquia entre esses eixos, ao afirmar a centralidade das desigualdades baseadas em questões de classe em relação às demais formas de desigualdade (GIMENEZ, 2001; SKEGGS, 1997). Uma segunda abordagem recusa tais pressupostos e trata a questão da existência de possíveis hierarquias entre os diferentes eixos e desigualdade social como uma questão empírica, 
que deveria ser considerada ao situar o objeto de estudo em seu contexto sóciohistórico.

Gimenez ilustra a primeira perspectiva que promove a ampliação da extensão teórica da interseccionalidade ao associá-la às teorias de inspiração marxista que conferem a primazia à classe como principal relação de dominação. Para Gimenez, o fato de a interseccionalidade afirmar a equivalência de todos dos sistemas de dominação - o que seria uma obstrução à centralidade da classe, tendo por exemplo o fato de as demandas de minorias étnicas e mulheres estarem subordinadas a questões econômicas restringe seu alcance teórico.

A socióloga britânica Bev Skeggs faz uma crítica semelhante, ao colocar que a interseccionalidade propõe uma série de equivalências entre raça, gênero e classe e, portanto, oclui a lógica particular das lutas de classes (GRESSGARD, 2008, n. 6). Para Skeggs, que estuda a construção mútua de gênero, classe, nação e sexualidades, porém, sem se apresentar como parte da escola interseccional, a análise interseccional precisa se atentar mais às especificidades históricas das formações sociais para evitar de cair na armadilha do reducionismo. Como veremos, autoras(es) identificadas(os) com a segunda abordagem, a que busca ampliar a teoria interseccional ao integrá-la à teoria sociológica geral sem necessariamente afirmar hierarquias mais ou menos implícitas entre categorias de desigualdade, estão avançando o debate sobre o reducionismo e suas múltiplas formas e oferecendo vários caminhos que podem ser seguidos para evitá-las.

Contrária à proposta de Gimenez de conferir o status de predominantes às relações de classe, o status justificado em sua visão pelo fato de as demais relações estruturantes de desigualdades estarem sujeitas às questões econômicas- uma proposição que a meu ver leva a um passo atrás - os caminhos tomados por Knapp, Acker Walby e Hall oferecem a vantagem de ampliar o alcance teórico da interseccionalidade sem subordinar um tipo de sistema social (seja ele baseado em classe, raça ou gênero, listando apenas esses) a um sistema tido como superdeterminante. Abaixo, considerarei cada um desses caminhos.

Uma primeira proposta vem de Knapp. Em sua visão, ligar a interseccionalidade com o kit de ferramentas da teoria crítica mais geral, permitiria ir além das análises microssociológicas que são predominantes na literatura, para compreender melhor os aspectos estruturais da subjetivação e posições subjetivas estruturadas (KNAPP, 2005, p. 259). Segundo Knapp (2005, p. 360), a teoria feminista, mesmo que tenha trazido à luz a existência de múltiplas diferenças e desigualdades, parece mal equipada para 
considerá-las dentro de um panorama sociológico mais geral, enquanto os amplos sistemas interpretativos desenvolvidos pelas teorias sociais não reconhecem a multiplicidade e coincidência de eixos de desigualdade.

A perspectiva adotada por Acker (2006b) é um tanto quanto ambígua no sentido que, em alguns de seus escritos, ela sugere a primazia das desigualdades de classe sobre às demais e acredita ser necessário que as mesmas sejam combatidas primeiro para conseguir que as demais desapareçam. Em outros escritos, porém, ela ressalta que mesmo se a classe permanece no centro de sua análise, - uma posição que ela justifica apontando o fato de que a desigualdade de classe ainda pode ser considerada legítima tanto em níveis sociais quanto legais no início do século XXI, enquanto as desigualdades referentes ao gênero e raça são percebidas como discriminação - isso é apenas uma dimensão a ser considerada entre as outras como o tipo de análise preferido pode também ser iniciado pelo ponto de partida do gênero, da raça ou sexualidade (ACKER, 2006b).

Através de seu modelo - que poderia ser descrito como concêntrico, no sentido em que posiciona um eixo de divisão social em seu centro e depois examina as relações entre esse eixo e os demais - ela reconceitualiza a classe ao expandir o significado de seu caráter econômico, e examina como a classe está intimamente conectada ao gênero e à raça, e também gênero e raça/etnia, formas de diferenciação social também atravessam as relações de classe e contribuem para a sua produção e reprodução. Em suma, o modelo adotado por Acker parece, a nível formal, seguir a já conhecida abordagem sociológica de Smith, que coloca o gênero no coração da análise e procura compreendê-lo em toda a sua complexidade em um dado contexto (SILTANEN; DOUCET, 2008), um método que no final da linha revela as interações do gênero com outros sistemas de desigualdade social como classe e raça. Para Acker, iniciar a análise com um eixo de divisão social e estruturá-la envolta desse eixo distingue-se de uma compreensão desses eixos como mutuamente constitutivos. Mostrando suas ressalvas sobre a ideia de as relações sociais serem mutuamente constitutivas, ela afirma: "mesmo se o conceito de relações de classe conectado ao gênero e à raça (gendered and racized) representa classe, raça e gênero como intrinsecamente interconectados, esses conceitos também significam uma diferença que pode ser perdida de vista no esforço de abordálas como mutuamente constitutivas" (ACKER, 2006b, p. 51-52).

De sua parte, Walby (2007, p. 449) recomenda a ampliação do alcance teórico da interseccionalidade ao posicioná-la em uma teoria de sistemas, revisada e ajustada 
pelas contribuições da teoria da complexidade que ela define como "uma coleção de trabalhos que tratam de questões fundamentais da natureza dos sistemas e suas mudanças". Para ela, é possível melhorar essa abordagem "reducionista e segregacionista", que ela examina do trabalho de Yuval-Davis (2006), ao expandi-la em duas direções. Por um lado, a ligação entre diferentes sistemas de relações sociais e as maneiras como eles se afetam mutuamente pode ser melhor teorizada ao distinguir entre dois tipos de relações sociais: domínios institucionais como a economia, o regime político e a sociedade civil, e relações sociais como classe, gênero e etnia (WALBY, 2007, p. 454;459). Por outro lado, a ontologia específica de cada conjunto de relações sociais (classe, gênero e etnia) precisa ser teorizada de uma maneira mais completa. Ao invés de pensar que cada conjunto está fundado em uma base única (econômica para as relações de classe, a discursiva/cultural para relações de gênero, etc.), essas ontologias específicas devem ser examinadas com mais profundidade, a fim de incluir em cada um dos sistemas (classe, gênero, etnia), a totalidade dos domínios institucionais (economia, regime político e sociedade civil).

A perspectiva de Walby lembra, até certo ponto, a de Stuart Hall, a quem ela não se refere. É importante considerar a teoria da articulação de Hall, mesmo que seu trabalho mais influente, de difícil classificação, não se encaixe explicitamente no corpo da literatura interseccional. Com base no trabalho de Gramsci e Althusser, Hall (2007) propõe um modelo de relativa autonomia para os sistemas de gênero, classe e raça, isto é, sua dissociação analítica. A ideia da interseccionalidade das divisões sociais pode ser encontrada em seu trabalho, como demonstrado por esse curto extrato:

O fim do sujeito Negro essencial requer o reconhecimento de que as questões centrais acerca da raça sempre apareceram historicamente em articulação, em formação com outras categorias e divisões, e que elas nunca deixaram de cruzar e recruzar categorias de classe, gênero e etnia. (HALL, 2007, p. 207)

A teoria de Hall da articulação pode constituir um complemento interessante ou até mesmo indispensável à interseccionalidade, não só por que permite a manutenção de uma fluidez associada ao construtivismo social e à teoria pós-moderna (COLLINS, 1998, p. 259), mas também por que demonstra a relevância de análises que dirigem sua atenção às especificidades históricas da formação da raça, classe e gênero, ainda reconhecendo e examinando suas múltiplas interdependências ${ }^{12}$. Para Hall (1985, p. 94-

\footnotetext{
12 Pode-se ressaltar nesse âmbito que Hall compreende a identificação como um processo de articulação, um ponto de dobradiça onde as dinâmicas de múltiplas diferenças se unem.
} 
96), o posicionamento social do indivíduo nas estruturas de poder e relações sociais não necessariamente leva a formações ideológicas ou práticas políticas específicas; como resultado, deve-se levar em conta a articulação de diferentes manifestações da formação social (econômica, política, cultural) contida em cada sistema social de raça, classe e gênero. Como assinalado por Juteau (1994, p. 102-103), a teoria da articulação de hall, desenvolvida por ele em seu trabalho publicado na década de 1980 (ver HALL, 1980, 1985, 1986), permite evitar tanto o reducionismo horizontal, isto é, a inabilidade de compreender a relativa autonomia dos sistemas sociais de raça, classe e gênero e conceitua-los como analiticamente diferentes, e o reducionismo vertical, o descarte de todas as mediações entre as diferentes manifestações (econômicas, políticas e ideológicas) das formações sociais (HALL, 1986, p. 101).

\section{Conclusão}

A interseccionalidade constitui um ponto nodal no discurso feminista no sentido colocado por Laclau e Mouffre (1985), isto é, um signo cujo significado está em constante negociação (EGELANDO; GRESSGARD, 2007). Como observamos através dos debates sobre a genealogia da interseccionalidade, trata-se de uma área de disputa marcada por histórias concomitantes envolvendo diferentes atores e pontos de vista.

Se há um consenso entre as autoras(es) em reconhecer a significância da interseccionalidade por todos os avanços de conhecimento sobre a complexidade das desigualdades e identidades sociais, alguns, entretanto, apontam os limites teóricos do conceito, propondo distintos caminhos para resolvê-los. Vide a necessidade de uma teorização que contextualize e historicize as estruturas de poder que a interseccionalidade aspira analisar, a fim de evitar descrições a-históricas. Como o poder explicativo da interseccionalidade é insuficiente para abarcar tudo o que pretende, uma ligação da interseccionalidade com o rol de ferramentas das teorias sociológicas mais gerais parece necessário para ampliar o seu alcance teórico. Minha posição nesse debate teórico se alinha mais à perspectiva de uma relativa autonomia dos sistemas de desigualdade social, reconhecendo a sua utilidade e acomodando dissociações analíticas que são justificadas e historicizadas. Me parece particularmente promissor estabelecer uma conexão entre a perspectiva de Walby, que permite a teorização aprofundada das ontologias específicas de cada sistema de desigualdade social, e a teoria da articulação 
de Hall, que traz à luz a articulação das diferentes manifestações de formação social (econômicas, políticas, culturais) em cada sistema social de raça, classe e gênero.

Ademais, afirmo a necessidade de se fazer uso de conceitos mediadores, envoltos dos quais a interseccionalidade pode ser mais operacional. Como vimos, a aplicação prática da interseccionalidade à pesquisa exige tais conceitos mediadores, seja o self dialógico implementado por Buitelaar (2006) ou as formas de capital social teorizadas por Bordieu, que Skeggs (1997) brilhantemente aplica para analisar as interseções entre classe e gênero no processo de geração de subjetividades.

Finalmente, enfatizo a importância de não se reduzir a interseccionalidade a um processo estabilizado em uma direção programática. Como Davis aponta (2008, p. 72), a ambiguidade de uma teoria favorece o trabalho de síntese, enquanto seus aspectos incompletos levam os pesquisadores a testá-la em novos campos de aplicação. Frente à grande diversidade de usos em diferentes campos de estudo e sob influências teóricas diferentes, seria, nesse aspecto, apropriado tratar a interseccionalidade como um metaprincípio que requer ajustes e adaptações de acordo com os campos de estudo e objetivos de pesquisa específicos aos quais se aplica, e aceitar a multiplicidade de seus usos.

\section{Referências}

Acker, J. (2006a) 'Inequality Regimes: Gender, Class, and Race in Organizations,' Gender and Society, 20(4): 441-464.

Acker, J. (2006b) Class Questions, Feminist Answers. Lanham: Rowman \& Littlefield.

Anthias, F. and Yuval-Davis, N. (1992) Racialized Boundaries: Race, Nation, Gender, Colour \& Class and the Anti-Racist Struggle. London: Routledge.

Bakhtin, M. (1981) The Dialogic Imagination. Four Essays. Austin: Texas UP.

Bilge, S. (in press) 'De l'analogie à l'articulation: théoriser la domination sociale et l'inégalité complexe,' L'homme et la société.

Brah, A. and Phoenix, A. (2004) 'Ain't I a Woman? Revisiting Intersectionality,', Journal of International Women's Studies, 5(3): 75-86.

Buitelaar, M. (2006) "I am the Ultimate Challenge". Accounts of Intersectionality in the Life-Story of a Well-Known Daughter of Moroccan Migrant Workers in the Netherlands,' European Journal of Women's Studies 13(3): 259-276.

Collins, P. H. (1998) Fighting Words: Black Women and the Search for Justice. Minneapolis: Minnesota UP.

Collins, P. H. (2000) Black Feminist Thought: Knowledge, Consciousness, and the Politics of Empowerment [1990].

New York: Routledge.

Collins, P. H. (2009) 'Foreword. Emerging Intersections. Building Knowledge and Transforming Institutions,' in B. Dill and R. Zambana (eds) Emerging Intersections. Race, Class and Gender in Theory, Policy and Practice, p. VII-XIII. New Brunswick, NJ: Rutgers UP. 
Crenshaw, K. (1989) 'Demarginalizing the Intersection of Race and Sex: a Black Feminist Critique of Discrimination Doctrine, Feminist Theory and Antiracist Practice,' University of Chicago Legal Forum, 89: 139-167.

Crenshaw, K. (1991) 'Mapping the Margins: Intersectionality, Identity Politics, and Violence against Women of Color,' Stanford Law Review, 43(6): 1241-1299.

Davis, K. (2008) 'Intersectionality as Buzzword: A Sociology of Science Perspective on What Makes a Feminist Theory Successful,' Feminist Theory, 9(1): 67-85.

Denis, A. (2008) 'Intersectional Analysis: A Contribution of Feminism to Sociology,' International Sociology, 23(5): 677-694.

Derrida, J. (1990) 'Some Statements and Truisms about Neologisms, Newisms, Postisms, Parasitisms and other Small Seismisms,' in David Carroll (ed.) The States of Theory: History, Art, and Critical Discourse, p. 63-95. Stanford, CA: Stanford UP.

Dill, B. T. and Zambana, R. E. (2009) 'Critical Thinking about Inequality. An Emerging Lens,' in B. T. Dill and R. E. Zambana (eds) Emerging Intersections. Race, Class and Gender in Theory, Policy and Practice, p. 1-21. New Brunswick, NJ: Rutgers UP.

Egeland, C. and Gressgård, R. (2007) 'The "Will to Empower": Managing the Complexity of the Others,' Nora. Nordic Journal of Women's Studies, 15: 207-219.

Faber, S. T. (2005) 'Towards an Intersectional Analysis of Gender and Class on the Basis of Bourdieu's Sociology,' Aalborg: Aalborg University, www.ruc.dk/upload/application/pdf/dae84ec7/Faber.pdf. Foucault, M. (1997) Il faut défendre la société. Cours au Collège de France, 1975-1976. Paris: Gallimard-SeuilEHESS.

Gimenez, M. (2001) 'Marxism and Class, Gender and Race: Rethinking the Trilogy,' Race, Gender and Class, 8(2): 23-33.

Gressgård, R. (2008) 'Mind the Gap: Intersectionality, Complexity and "the Event",' $\begin{array}{lll}\text { Theory and } & \text { Science, } & 10(1):\end{array}$ theoryandscience.icaap.org/content/vol10.1/Gressgard.html.

Hall, S. (1980) 'Race, Articulation and Societies Structured in Dominance,' in Coll., Sociological Theories: Race and Colonialism, p. 305-345. Paris: UNESCO.

Hall, S. (1985) 'Signification, Representation and Ideology; Althusser and the Poststructuralist Debates,' Critical Studies in Mass Communication, 2(2): 91-114.

Hall, S. (1986) 'Gramsci's Relevance for the Study of Race and Ethnicity,' Journal of Communication Inquiry, 10(2): 5-27.

Hall, S. (1997) 'The Spectacle of the "Other",' in S. Hall (ed.), Representation: Cultural Representations and Signifying Practices, p. 223-279. London: Sage/Open UP.

Hall, S. (2007) 'Nouvelles ethnicités' [1989], in Id., Identités et cultures. Politiques des Cultural Studies, p. 203-213. Paris: Amsterdam.

Hancock, A-M. (2007) 'Intersectionality as a Normative and Empirical Paradigm,' Politics and Gender, 3(2): 248-254.

Hankivsky, O. and Christoffersen, A. (2008) 'Intersectionality and the Determinants of Health: a Canadian Perspective,' Critical Public Health, 18(3): 271-283.

Henderson, D. and Tickamayer, A. (2009) 'The Intersection of Poverty Discourses: Race, Class, Culture and Gender,' in B. Dill and R. Zambana (eds) Emerging Intersections. Race, Class and Gender in Theory, Policy and Practice, p. 73-100. New Brunswick, NJ: Rutgers UP.

Hermans, H. and Kempen, H. (1993) The Dialogical Self: Meaning as Movement. San Diego, CA: Academic Press.

Juteau, D. (1994) 'De la fragmentation à l'unité: vers l'articulation des rapports sociaux,' L'égalitarisme en question. Cahiers de recherche éthique, 18: 81-108. 
Knapp, G.-A. (2005) 'Race, Class, Gender: Reclaiming Baggage in Fast Travelling Theories,' European Journal of Women's Studies, 12: 249-265.

Knudsen, S. V. (2006) 'Intersectionality - A Theoretical Inspiration in the Analysis of Minority Cultures and Identities in Textbooks,' in Caught in the Web or Lost in the Textbook? 8th International Conference on Learning and Educational Media, www.caen.iufm.fr/colloque_iartem/pdf/knudsen.pdf.

Kofoed, J. (2008) 'Appropriate Pupilness: Social Categories Intersecting in School,' Childhood, 15(3): 415-430.

Laclau, E. and Mouffe, C. (1985) Hegemony and Socialist Strategy. London: Verso.

Mann, S. A. and Huffman, D. J. (2005) 'The Decentering of Second Wave Feminism and the Rise of the Third Wave,' Science and Society, 69(1): 56-91.

Maynard, M. (1994) "Race", Gender and the Concept of "Difference" in Feminist Thought,' in H. Afshar and M. Maynard (eds) The Dynamics of 'Race' and Gender: Some Feminist Interventions, p. 9-25, London: Taylor \& Francis.

McAll, C. (1990) Class, Ethnicity and Social Inequality. Montreal \& Kingston: McGillQueen's UP.

McCall, L. (2005) 'The Complexity of Intersectionality,' Signs: Journal of Women in Culture and Society, 30(3): 1771-1800.

Prins, B. (2006) 'Narrative Accounts of Origins: A Blind Spot in the Intersectional Approach?' European Journal of Women's Studies, 13(3): 277-290.

Siltanen, J. and Doucet, A. (2008) Gender Relations in Canada. Intersectionality and Beyond. Toronto: Oxford UP.

Skeggs, B. (1997) Formations of Class and Gender. London: Sage Publications.

Stasiulis, D. (1999) 'Feminist Intersectional Theorizing,' in P. Li (ed.), Race and Ethnic Relations in Canada, p. 347-397. Toronto: Oxford UP.

Staunæs, D. (2003) 'Where have All the Subjects Gone? Bringing Together the Concepts of Intersectionality and Subjectification,' Nora. Nordic Journal of Women Studies, 11: 101-110.

Therborn, G. (2000) 'At the Birth of Second Century Sociology: Times of Reflexivity, Spaces of Identity and Nodes of Knowledge,' British Journal of Sociology, 51: 37-59. Vakulento, A. (2007) "Islamic Headscarves" and the European Convention on Human Rights: An Intersectional Perspective,' Social Legal Studies, 16: 183-199.

Walby, S. (2007) 'Complexity Theory, Systems Theory, and Multiple Intersecting Social Inequalities,' Philosophy of the Social Sciences, 37(4): 449-470.

Weber, L. (2001) Understanding Race, Class, Gender and Sexuality: A Conceptual Framework. New York: McGraw-Hill.

Weber, L. and Parra-Medina, D. (2003) 'Intersectionality and Women's Health: Charting a Path to Eliminating Health Disparities,' in M. Texler Segal, V. Demos, and J. Jacobs Kronenfeld (eds) Gender Perspectives on Health and Medicine: Key Themes, p. 181-229. Oxford: Elsevier.

Yuval-Davis, N. (2006) 'Intersectionality and Feminist Politics,' European Journal of Women's Studies, 13(3): 193-209.

Artigo traduzido em 25 de novembro de 2020. Aprovado em 26 de novembro de 2020. 